\title{
Dramaturgi Identitas Perempuan Penggemar Karya Fiksi Homoseksual (Boys Love) di Indonesia
}

\author{
Mega Hidayati ${ }^{1}$, Medhy Aginta Hidayat ${ }^{*}$
}

1 Universitas Trunojoyo Madura, Indonesia

\author{
A R T I C L E I N F O \\ Article history: \\ Received 12 September \\ 2021 \\ Accepted 03 November \\ 2021 \\ Available online 01 \\ December 2021 \\ Kata Kunci: \\ Dramaturgi; Identitas; \\ Fujoshi; Homoseksual; \\ Boys Love \\ Keywords: \\ Dramaturgy; Identity; \\ Fujoshi; Homosexual; Boys \\ Love
}

menyembunyikan identitasnya sebagai pen lesbian yang bermakna negatif. Lebih jauh, fujoshi melakukan praktik dramaturgi dan negosiasi identitas agar tetap dapat hidup harmonis dalam lingkungan masyarakat Indonesia yang heteronormatif.

\section{A B S T R A C T}

This article examines the dramaturgical practices of the identity of fujoshi or female fans of homosexual fiction (Boys Love) in Indonesia. Fujoshi is a Japanese term that means heterosexual women who are fans of homosexual fiction. This study aims to explain the forms of dramaturgical practices carried out by fujoshi as heterosexual women and, at the same time, fans of homosexual fiction. This study uses a qualitative approach with the ethnographic method. The data were obtained through participative observation and in-depth interviews with 20 informants. The data were analyzed using the thematic method to understand the informants' dramaturgical experiences. This study found that fujoshi practice dramaturgical identity negotiation by presenting a double-identity in the front-stage and back-stage: in public, they present themselves as heterosexual women; in the private life, they appear as consumers of homosexual stories. Because of their minority position, fujoshi often hide their identity as fans of homosexual fiction to avoid being labeled as a lesbian, which has a negative stigma in Indonesian society. Fujoshi, also has to practice identity negotiations in order to live harmoniously in a heteronormative Indonesian society. 


\section{Pendahuluan}

Di era globalisasi saat ini berbagai macam kebudayaan asing masuk dan membawa pengaruh ke Indonesia. Salah satu kebudayaan asing yang masuk ke Indonesia adalah budaya populer yang berasal dari Jepang. Negeri Sakura tersebut terkenal akan berbagai produk budaya populer seperti musik (J-Pop, J-Rock), gaya berbusana (Harajuku Style), hingga anime (animasi) dan manga (komik). Di Indonesia, anime dan manga banyak diminati, terbukti dengan banyaknya situs-situs di internet yang memuat konten anime dan manga, serta banyaknya fanpage dan grup-grup penggemar anime dan manga di media sosial. Anime dan manga memiliki banyak genre, salah satu genre yang unik adalah Boys Love (selanjutnya BL) (Turner, 2016). Konten cerita genre BL mempertemukan dua orang laki-laki yang divisualisasikan sebagai lakilaki yang cantik (dalam bahasa Jepang disebut Bishōnen) (Su, 2019).

Di dunia anime dan manga, BL termasuk genre yang menyasar para perempuan muda atau dalam bahasa Jepang disebut Manga Shōjo. Karena target pasarnya merupakan perempuan muda atau bisa dikatakan remaja perempuan, manga-manga BL di Jepang sebagian besar dibuat dan ditujukan untuk perempuan (McLelland et al., 2015). Di Indonesia, komik bergenre BL mulai ada sejak tahun 2000-an (Abraham, 2010). Komik dan novel BL yang tersedia di Indonesia mayoritas bergenre Shonen $A i$ yaitu genre BL dengan muatan seksual implisit. Meskipun cenderung sulit didapatkan di toko-toko buku resmi, namun komik dan novel BL dapat ditemukan di situs jual beli daring. Berbeda dengan di Jepang yang dapat lebih menerima karya fiksi BL, di Indonesia para penggemar BL bergantung pada internet untuk memperoleh kontenkonten BL, khususnya untuk drama dan animasi BL. Mereka mendapatkan karya fiksi BL dari situs-situs seperti AarinFantasy, Mangago, JuneManga, NovelUpdates, MTLNovel,MangaPark atau dari aplikasi seperti WebToon, Wattpad, Youtube, Telegram, dan lain sebagainya. Selain media internet sebagai sumber utama untuk memperoleh konten BL, platform media sosial juga berperan penting sebagai media interaksi antara sesama penggemar karya fiksi homoseksual. Biasanya mereka berinteraksi melalui Facebook, WhatsApp, Instagram, Line, Telegram, dan bergabung atau membentuk grup khusus untuk dapat saling berkomunikasi dan membagikan informasi-informasi seputar BL.

Sejak sekitar tahun 2000, para perempuan penikmat konten-konten homoseksual (anime dan manga) di Jepang memiliki julukan baru yaitu Fujoshi (腐女子) (Sugiura, 2006). Dalam bahasa Jepang, Fu memiliki arti busuk dan Joshi dapat berarti gadis atau wanita. Diberi julukan busuk karena alih-alih menghindari hal atau problematika yang bertentangan dengan seksualitas perempuan (kisah percintaan antara sesama lelaki yang dianggap "busuk"), justru para perempuan ini merangkul "kebusukan" tersebut menjadi suatu hal yang mereka gemari (McLelland et al., 2015).

Para fujoshi biasanya menyembunyikan identitas mereka sebagai perempuan yang menggemari konten-konten BL. Hal ini dikarenakan pandangan masyarakat yang masih tabu terhadap percintaan sesama jenis, misalnya seperti di Indonesia. Kegemaran terhadap bacaan dan tontonan yang berisikan konten seksual antara pasangan normal yaitu laki-laki dan perempuan saja seringkali dicap negatif, apalagi menggemari konten-konten homoseksual. Aquarini (dalam Winduwati, 2015) berpendapat bahwa di Indonesia isu homoseksualitas belum bisa diterima karena dianggap sebagai sebuah penyimpangan dari patokan normal hubungan romantisme dan erotisme manusia. Homoseksualitas kemudian digambarkan sebagai dosa atau penyakit yang harus disembuhkan (Husaini, 2015) .

Dalam kehidupan sehari-hari, fujoshi di Indonesia cenderung memiliki identitas ganda. Dualisme identitas fujoshi terlihat pada dua peran yang berbeda dalam dua dunia yang berbeda pula. Di satu sisi, fujoshi adalah para perempuan heteroseksual yang hidup dalam masyarakat dan menganut prinsip heteronormatif. Di sisi lain, fujoshi menggemari konten-konten karya fiksi homoseksual ketika berada di dunia maya dan cenderung mereka sembunyikan karena pandangan masyarakat Indonesia yang menganggap tabu orientasi seks homoseksual. Para fujoshi memanfaatkan media sosial sebagai sarana untuk berinteraksi dengan sesama fujoshi, membangun dunia tersendiri dan sekaligus sebagai tempat memerankan identitas kedua mereka. Fenomena kehidupan dramaturgis para fujoshi di Indonesia yang sebenarnya sangat 
menarik ini sayangnya belum banyak dikaji secara ilmiah, terutama dalam perspektif sosiologis. Dari uraian latar belakang seperti telah dipaparkan di atas, maka penelitian ini bertujuan untuk menjelaskan bagaimana bentuk-bentuk praktik dramaturgi identitas yang dilakukan oleh para fujoshi di Indonesia dalam kehidupan sehari-hari mereka sebagai perempuan heteroseksual pada umumnya dan sekaligus perempuan heteroseksual yang menggemari konten-konten cerita fiksi homoseksual.

\section{Metode}

Metode yang digunakan dalam penelitian ini adalah netnografi. Netnografi merupakan metode penelitian kualitatif yang berfokus pada komunitas dan budaya yang ada di dunia maya atau internet (Kozinets, 2010). Pendekatan netnografis adalah metode yang banyak digunakan untuk mempelajari forum daring, obrolan daring, grup berita di internet, blog, audiovisual, fotografi, komunitas siniar (podcast), dunia virtual, pemain game berjaringan, seluler komunitas, dan situs jejaring sosial (Kozinets, 2015).

Data etnografi dalam penelitian ini diperoleh melalui observasi partisipatif dan wawancara mendalam secara daring terhadap 20 informan fujoshi anggota grup WhatsApp FR (nama grup fujoshi diinisialkan FR untuk kepentingan menjaga privasi). Grup WhatsApp FR merupakan grup WA yang beranggotakan para fujoshi atau mereka yang gemar membaca konten-konten fiksi homoseksual. Grup WhatsApp FR ini dibuat oleh Tonny (nama disamarkan oleh peneliti) pada 1 Juni 2020 dan kini beranggotakan sebanyak 128 orang. Informan dalam penelitian ini dipilih dengan menggunakan teknik snowball sampling dengan memperhatikan kriteria sebagai berikut: (1) perempuan heteroseksual; (2) merupakan fujoshi atau penggemar karya fiksi homoseksual; dan (3) menjadi anggota aktif grup WhatsApp FR. Wawancara secara daring dilakukan melalui WhatsApp Message dan WhatsApp Video, dengan setiap wawancara berdurasi antara satu hingga tiga jam.

Data hasil wawancara yang diperoleh selanjutnya ditranskripsi dan dilakukan coding untuk mempermudah proses analisis data. Data yang diperoleh dalam penelitian ini dianalisis dengan menggunakan teknik thematic analysis. Dalam teknik ini, data dibaca sebagai sekumpulan teks dengan tema-tema khusus tertentu yang diharapkan dapat menjawab pertanyaan penelitian (Siyoto\&Sodik, 2015). Setelah data ditranskripsi, dilakukan reduksi data yang tidak diperlukan dan selanjutnya dilakukan pengkodean sesuai tema-tema yang paling sering muncul dalam hasil wawancara. Temuan berupa tema-tema ini selanjutnya dikelompokkan untuk menjawab rumusan masalah penelitian terutama melalui pengalaman fenomenologis para informan.

Data hasil wawancara yang telah dikelompokkan berdasarkan tema-tema tertentu selanjutnya dijelaskan dan diinterpretasikan dengan bantuan teori yang telah dipilih, yakni teori dramaturgi dari Erving Goffman (Goffman, 1959). Selain itu, temuan penelitian ini juga didialogkan dengan hasil-hasil penelitian terdahulu yang telah dilakukan oleh sejumlah peneliti lain. Dari proses analisis data secara dialektis ini selanjutnya peneliti mengambil kesimpulan untuk menjawab pertanyaan penelitian tentang praktik dramaturgi identitas fujoshi di Indonesia yang diharapkan dapat mengembangkan body of knowledge kajian budaya populer dan sosiologi identitas di Indonesia.

\section{Hasil dan Pembahasan}

Penelitian ini menggunakan teori dramaturgi untuk melihat bagaimana fujoshi atau perempuan penggemar karya-karya fiksi homoseksual melakukan praktik dramaturgi dan negosiasi identitas. Dramaturgi adalah teori yang dikemukakan oleh Erving Goffman pada tahun 1956. Dalam teori dramaturgi Goffman berpendapat bahwa individu merupakan aktor yang sedang memerankan peran-peran tertentu sesuai dengan harapan dalam "panggung" masyarakat (Goffman, 1959). Goffman menguraikan pemikirannya tentang dramaturgi melalui enam prinsip utama yaitu kinerja, tim, wilayah, peran, komunikasi keluar dari karakter, dan manajemen kesan (Manning, 1992). Dalam penelitian ini peneliti menggunakan keenam prinsip 
ini untuk melihat praktik dramaturgi identitas dalam diri fujoshi atau perempuan heteroseksual yang menggemari konten-konten homoseksual.

Prinsip pertama dalam teori dramaturgi adalah kinerja, yaitu aktivitas individual pada satu periode yang ditandai dengan kehadirannya terus menerus di hadapan sekelompok pengamat tertentu dan memiliki pengaruh pada pengamat tersebut (Goffman, 1959). Dengan kata lain, kinerja ini merupakan representasi diri individu di hadapan kelompok tertentu. Dari delapan informan fujoshi, peneliti mengelompokkannya menjadi tiga tipologi fujoshi berdasarkan identitasnya seperti terlihat pada Tabel 1.

Tabel 1. Tipologi Fujoshi Berdasarkan Identitasnya

\begin{tabular}{|c|c|}
\hline Nama Informan & Tipe Fujoshi (Berdasarkan Identitasnya) \\
\hline Michan & Menyembunyikan \\
\hline Sisca & Menyembunyikan \\
\hline Julay & Menyembunyikan \\
\hline Daisy & Menyembunyikan \\
\hline May & Kondisional \\
\hline Caroline & Kondisional \\
\hline Akane & Tidak menyembunyikan \\
\hline Calvin & Tidak menyembunyikan \\
\hline
\end{tabular}

Sumber: Diolah dari data primer (2021)

Sebanyak empat informan dalam penelitian ini menyembunyikan identitasnya sebagai fujoshi, dua informan tidak menyembunyikan identitas fujoshi-nya, dan dua lainnya bersifat kondisional (melihat terlebih dahulu tipe orang-orang di sekitarnya, jika dirasa homofobik maka informan akan menyembunyikan identitas fujoshi-nya).

Fujoshi dengan tipologi menyembunyikan identitas dan kondisional, otomatis memiliki dua kinerja yang berbeda, karena mereka harus merepresentasikan dirinya di dua kelompok yang berbeda. Pada kelompok pertama, yaitu masyarakat dan keluarga, fujoshi merepresentasikan dirinya sebagai perempuan heteroseksual pada umumnya, mematuhi aturan yang berlaku di masyarakat dan menganut prinsip heteronormatif:

"Hmmm aku lihat-lihat orang Meg, kalau sepertinya orangnya berpandangan terbuka kalau somehow mereka tau ya aku ngaku aja. Tapi ada beberapa orang yang aku lihat terlalu kaku, aku memang tidak cerita. Sehari-harinya yah aku biasa sebagai professional career woman. Orang kantor sih kebanyakan tau dan paham kalau aku fujo." (wawancara dengan Caroline, 24 Februari 2021)

"Kalau keluarga nggak ada yang tau emang. Kalau tau bisa diceramahin tujuh hari tujuh malem yang ada. Apalagi Mak-ku tuh pikirannya gak tolerir ama hal yang nggak biasa (homoseksual)." (wawancara dengan Michan, 21 Februari 2021)

Pada kelompok pertama ini fujoshi bisa berperan sesuai perannya, misalnya, sebagai siswi, mahasiswi, wirausahawati, atau karyawati yang juga menyukai lawan jenis, menjalankan aturan, dan nilai agama yang dianut. Temuan ini selaras dengan hasil penelitian yang dilakukan oleh Dewi Nur Tadzakaroh yang berjudul Perempuan, Identitas dan Komik Homoerotis, yang menemukan bahwa mayoritas fujoshi cenderung merahasiakan identitas fujoshi-nya atau tidak merepresentasikan identitas fujoshi-nya di kalangan masyarakat atau sering disebut dengan istilah living anonymous (Tadzakaroh, 2017). Latar atau panggung disini mempengaruhi identitas dari informan. Goffman berpendapat dalam pemikirannya mengenai stigma, identitas individu dibagi menjadi dua yaitu virtual identity yaitu identitas yang diperankan di panggung belakang, dan actual identity yang diperankan di panggung depan (Goffman, 1963). 
Sedangkan kelompok kedua dalam kinerja fujoshi adalah kelompok-kelompok fujoshi di media sosial, salah satunya adalah grup WhatsApp FR (WA FR). Dalam grup WA FR, para informan dalam penelitian ini dengan bebas dapat merepresentasikan diri sebagai perempuan yang menggemari konten-konten homoseksual. Perspektif, asumsi, fantasi bebas dilontarkan para fujoshi di grup WA FR tanpa takut akan adanya justifikasi negatif terhadap dirinya. Informan bahkan akan berusaha agar dirinya dapat diterima di grup WA FR yang merupakan dunia keduanya.

Dalam konteks ini, internet merupakan sumber utama bagi para fujoshi untuk mendapatkan karya-karya fiksi BL, termasuk dalam grup-grup di media sosial seperti grup FR yang merupakan tempat para fujoshi untuk saling berinteraksi dan berbagi karya-karya fiksi homoseksual. Minimnya sumber langsung seperti toko buku atau bioskop di Indonesia yang menyediakan karya fiksi homoseksual menjadikan media internet sebagai pilihan untuk memenuhi kegemaran para fujoshi. Dalam artikel yang berjudul Fantasy Play and Transgressive Intimacy among Rotten Girls in Contemporary Japan, Patrick W. Galbraith menjelaskan bagaimana fujoshi di Jepang mampu membangun interaksi yang intim atau dekat satu sama lain dan membentuk komunitas di internet untuk memenuhi kebutuhan fantasi mereka dengan membuat konten-konten fiksi homoseksual untuk kalangan mereka sendiri atau sering disebut sebagai doujinshi (Galbraith, 2011)

Grup WA FR merupakan dunia kedua bagi para fujoshi dalam penelitian ini, walaupun tergolong hanya sebagai dunia maya. Grup di media sosial dipilih oleh para informan ini karena bebas dari intervensi publik. Dalam grup WA FR aktivitas yang dilakukan bermacam-macam mulai dari berbagi informasi seputar konten BL, bercerita masalah pribadi, promosi akun media sosial dan bisnis, serta pembahasan mengenai topik LGBT. Hal ini juga peneliti temui terkait pandangan homoseksual para fujoshi, yang berdasarkan observasi tidak hanya ada pada grup WA FR namun juga pada grup fujoshi lainnya. Terlepas dari fujoshi yang memiliki pandangan menolak homoseksualitas atau fujoshi yang cenderung bersikap ambivalen terhadap homoseksualitas, pada saat pertama kali bergabung dalam grup-grup fujoshi maka mereka cenderung bersikap mendukung homoseksualitas.

Peneliti sempat menemukan keributan (war) dalam grup fujoshi lain (bukan grup WA FR) yang dipicu oleh perbedaan pandangan terhadap homoseksualitas. Akhirnya konflik diselesaikan dengan kesepakatan ketika membahas perihal pandangan terhadap homoseksualitas akan menjadi urusan pribadi masing-masing individu, dan tidak boleh membawa aturan-aturan agama saat di dalam grup. Lebih lanjut mereka (fujoshi dalam grup) menekankan bahwa grup fujoshi ini hanyalah sebagai hiburan dan tidak mencari apa, atau siapa, yang benar dan salah:

"Kalau gabung ke grup fujo kan mau gak mau artinya kitanya suka sama konten BL entah di dalem hati nurani kita merasa salah atau nggaknya. Nggak mungkin kita di dalem grup bilang aku menolak LGBT, tapi kitanya masuk grup BL. Lak yo lucu to (kan ya lucu). Kecuali kalau kayak aku udah dapet temen fujo yang deket dan terbuka pikirannya, ya aku bisa ungkapin pendapat aku tentang homoseksual gimana ke dia." (wawancara dengan Sisca, 1 Mei 2021)

"Ya kita hargai aja sih Bun (Bunda) pendapat orang lain. Cuman kalok agama dibawa emang gak abis pembahasannya jadinya. Ya udah tau lah kalok ini salah sih (BL) cuman ya balik lagi kan elunya suka konten BL nih ceritanya. Ya udah gitu lah pokoknya Bun, mau ngejelasinnya gimana jugak. Wkwkwkwk." (wawancara dengan Calvin, 25 Februari 2021)

Bagi tipologi fujoshi yang tidak menyembunyikan identitas fujoshi-nya maka kinerja yang ia lakukan tidak mengalami perbedaan. Fujoshi yang terbuka pada publik memiliki prinsip jika memang orang lain tidak suka dengan kegemarannya, maka bebas untuk tidak menyukainya bahkan beberapa anggota keluarga informan mengetahui bahwa ia adalah seorang fujoshi: 
"Iya aku sempet si nyembunyiin kalok aku fujo gak sampek setahunan lah. Abis itu enggak soalnya aku malah mikir selera ku keren karena beda. Suami tau, saudara juga banyak yang tau. Komentar negatif itu ada, ada yang sampek ngeblok kontakku" (wawancara dengan Akane, 26 Februari 2021)

Representasi diri juga melibatkan prinsip kedua dalam dramaturgi yakni tim, sebagai konsep kelompok dimana aktor tergabung dan menampilkan sebuah pertunjukan. Informan dalam penelitian ini memiliki dua tim atau kelompok yang harus diikuti, yaitu keluarga dan masyarakat sebagai kelompok pertama, sedangkan kelompok kedua adalah grup WA FR dan grup-grup fujoshi lainnya. Dalam teori dramaturgi seorang aktor harus menjaga rahasia dan mengelola kesan yang dimiliki oleh timnya. Jika informan tidak sedang menjadi fujoshi, maka ia akan bersikap seperti apa yang diharapkan oleh masyarakat dan keluarganya, serta sesuai dengan nilai, norma, agama dan budaya yang berlaku. Namun, jika informan sedang menjadi fujoshi maka ia akan menjadi perempuan heteroseksual (straight woman) yang menggemari konten BL, saling berbagi informasi, konten, dengan anggota kelompok lainnya yaitu grup WA FR dan menjaga rahasia yang dimiliki oleh grup. Salah satu caranya adalah dengan tidak membagikan tautan grup tanpa izin admin, dan tidak menyebarkan aktivitas yang ada di dalam grup WA FR:

"Kan dulu sempet ya ada kejadian grup fujo tuh ke up (ditayangkan) di Net (Net TV). Terus beritanya tuh kayak ngejadiin fujo jelek banget, padahal gak gitu sebenernya. Dulu pada takut grup-grup banyak bubar, nah makanya kalau mau jadi mem (member) di FR harus melalui aku. Biar aku tau anaknya kayak gimana, dapet infonya dari mana." (wawancara dengan Tonny, 1 Mei 2021)

Menurut peneliti, dalam dua kelompok tersebut, yakni keluarga dan masyarakat di satu sisi, serta grup WA FR di sisi lain, delapan informan sebagai fujoshi selalu berperan menyesuaikan posisi dirinya sedang berada pada kelompok yang mana. Saat sedang berada pada kelompok pertama yaitu keluarga dan masyarakat, misalnya, informan Michan, Sisca, Julay, Daisy yang menyembunyikan dirinya sebagai fujoshi, memposisikan dirinya sebagai perempuan heteroseksual yang tidak menggemari konten homoseksual, bahkan tidak mendukung homoseksualitas. Begitu juga dengan informan tipe fujoshi kondisional, misalnya, seperti May dan Caroline, dan tipe yang tidak menyembunyikan identitas fujoshi-nya, misalnya, seperti Calvin dan Akane, mereka juga melakukan hal yang sama. Hal tersebut terutama dikarenakan adanya aturan agama dan prinsip heteronormativitas yang dominan dianut oleh masyarakat Indonesia. Para informan dalam penelitian ini takut dianggap aneh atau memiliki kelainan secara psikologis dan menyimpang. Selain itu ada nama baik dan kesan kelompok yang harus mereka jaga misalnya keluarga, sekolah, kampus, agama, dan perusahaan. Dalam hal ini identitas informan sebagai fujoshi merupakan virtual identity yang seharusnya tidak diketahui oleh penonton (masyarakat, keluarga, rekan kerja) (Goffman, 1963), sehingga praktik dramaturgi diperlukan untuk menghindari stigma yang tidak diinginkan oleh informan.

Prinsip ketiga dramaturgi yang ditemukan dalam penelitian ini adalah perihal wilayah yang terbagi menjadi dua bagian, yaitu wilayah depan (front-stage) dan wilayah belakang (backstage). Wilayah depan (front-stage) merupakan panggung bagi aktor untuk berperan sesuai dengan harapan penonton. Dalam hal ini fujoshi berperan sesuai dengan konstruksi normatif masyarakat pada umumnya terhadap perempuan. Jika dilihat memang secara sikap dan sifat fujoshi tidak berbeda dengan perempuan lainnya: mereka beribadah, memiliki pacar atau suami laki-laki, feminim, bergaul dengan teman-temannya, berpenampilan seperti kebanyakan perempuan pada umumnya. Informan Akane, misalnya, saat tidak menjadi fujoshi ia menjalankan tugasnya sebagai seorang ibu rumah tangga. Hal yang sama juga dilakukan oleh informan Caroline saat ia tidak menjadi fujoshi, ia adalah wanita karir yang juga harus mengurus suaminya. Akan sulit untuk melihat perbedaan atau mengetahui apakah seorang perempuan adalah fujoshi atau tidak jika ia tidak mengatakan sendiri: 
"Ya sehari-harinya aku biasa aja sih soalnya kan jadi fujo ama ngga jadi fujo ngga ada bedanya. Tapi ada satu hal kalau pas nonton BL susah banget buat ibadah kek nanti-nanti dulu gitu loh, nonton BL aja dulu. Dari segi mood juga sih kalau ngefujo tuh kadang kebawa perasaan ama crita (cerita) di film atau manhua." (wawancara dengan Michan, 21 Februari 2021)

Wilayah kedua dalam dramaturgi adalah wilayah belakang (back-stage), tempat aktor mempersiapkan dirinya sebelum memainkan perannya di panggung depan (front-stage). Goffman berpendapat bahwa di wilayah belakang aktor seringkali menunjukkan sisi diri yang tidak ia tampilkan di panggung depan, yaitu rahasia (Goffman, 1959). Di wilayah belakang ini informan fujoshi sudah tidak memainkan perannya sebagai perempuan sesuai standar masyarakat, yang seharusnya seorang perempuan heteroseksual mengikuti prinsip heteronormativitas. Di panggung belakang informan bebas untuk tidak mematuhi prinsip heteronormativitas. Para informan yang merupakan perempuan heteroseksual ini membuka "rahasia" diri mereka sebagai penggemar konten-konten fiksi homoseksual. Tidak hanya itu, informan juga bebas memandang fenomena LGBT khususnya homoseksual menurut sudut pandangnya sendiri tanpa harus mendapat intervensi dari pihak lain. Ini berbeda saat di panggung depan, informan tidak bisa bebas menyampaikan pendapat atau pemikirannya tentang homoseksual karena harus menjaga kesan kelompok pertamanya yaitu keluarga dan masyarakat. Di dunia belakang informan bebas mengekspresikan kegemarannya tanpa harus berpura-pura menjadi diri yang orang lain inginkan.

Bagi tipologi fujoshi yang tidak menyembunyikan identitasnya, mereka terkadang mengkonsumsi konten-konten fiksi homoseksual saat berada di area publik. Namun, ketika terdapat adegan kontak langsung antara kedua aktor (skinship) dan mengarah pada adegan seksual, informan akan melewatkan (skip) adegan tersebut, atau melanjutkan mengkonsumsi konten BL tersebut saat ia sendirian. Selain itu, semua informan dalam penelitian ini juga melakukan privasi keamanan pada telepon genggam mereka untuk menghindari orang lain mengakses telepon genggamnya:

"Ya tergantung waktu gua nontonnya sihh, kalok belum selesai nontonnya (ketika sendirian) nontonnya di publik pokoknya mana (pas) ada waktu kosong sih. Pas ada adegan ++ (plus-plus atau adegan dewasa) gua skip-skip dikit sih kalo di publik." (wawancara dengan Calvin, 22 Februari 2021)

"Ya pasti pas sendiri dong. Tadi nekat nonton pas di mobil dekat ustadz ehh kaga jadi soalnya adegan bobo bareng. Wkwkwkwk, berabe kalau ketahuan." (wawancara dengan Michan, 21 Februari 2021)

Di wilayah belakang ini beberapa informan juga melakukan apa yang disebut sebagai otome filter. Otome filter adalah proses mengimajinasikan situasi dan kondisi di kehidupan nyata atau real life (3D) menjadi kehidupan buatan di dunia fantasi (2D) (Tadzakaroh, 2017). Ketika sedang menjalani aktivitas sehari-hari, informan sebagai seorang perempuan pada umumnya dan menjumpai laki-laki yang memiliki visual menarik bahkan orang yang dekat dengan informan seperti teman, maka informan fujoshi akan berimajinasi atau membayangkan orang tersebut menjadi tokoh dalam cerita BL. Informan akan melakukan pemasangan atau pairing menjadi pasangan gay, dan kemudian berimajinasi seolah-olah orang tersebut adalah tokoh dalam cerita BL:

"Selama jadi fujo liat cowo-cowo (cowok) boncengan udah mikir duluan yang belakang itu uke. Liat cowo cewe pacaran b aja (biasa aja) tapi kalau liat bxb (Boys x Boys) omaigaattt." (wawancara dengan Julay, 22 Februari 2021) 
"Aku suka ngepair (memasangkan) sih, dulu suamiku korban pair. Tapi becandaan ya, waktu jadi temen dulu udah tau Meg (tahu bahwa informan seorang fujoshi) karena dari awal dia jadi korban (pairing)." (wawancara dengan Caroline, 24 Februari 2021)

Selain melakukan otome filter, beberapa informan mengaku bahwa ketika mereka sedang mengkonsumsi konten-konten $\mathrm{BL}$, mereka juga membayangkan dirinya menjadi salah satu pemeran atau karakter di dalam cerita tersebut. Hal ini sejalan dengan temuan penelitian Mark J. McLelland yang dipublikasikan dalam artikel yang berjudul The Love Between "Beautiful Boys" in Japanese Women's Comics (2000). McLelland menemukan bahwa kegemaran wanita Jepang terhadap konten-konten fiksi homoseksual merupakan bentuk resistensi terhadap dominasi patriarki yang kuat di Jepang. Adanya stigma bahwa perempuan merupakan mesin pembuat anak dan sebagai alat pemenuhan kebutuhan seks di Jepang, membuat mereka menggemari konten BL. Di dalam konten BL berlangsung apa yang disebut sebagai "kecairan identitas", dimana para penggemar perempuan ini dapat mengidentifikasi diri mereka sebagai salah satu karakter dalam konten BL tersebut (McLelland, 2000). Lebih lanjut, delapan informan dalam penelitian ini menyampaikan bahwa konten yang mereka konsumsi turut mempengaruhi emosi mereka. Ketika konten yang mereka konsumsi dalam suasana bahagia atau romantis, maka akan membuat mood mereka bagus. Sebaliknya, ketika konten sedang dalam suasana sedih, terjadi konflik antara pasangan dalam cerita BL, maka informan akan menjadi sedih bahkan menjadi mudah marah dalam kehidupan nyatanya.

"Ya ada sedikit perbedaan kek semenjak masuk dunia fujo gua lebih kek gila-gila gitu kata tementemen gua. Huahahahha. Suka senyum-senyum sendiri. Pas nonton konten BL ngaruh banget kesel sendiri sampe marah-marah nggak jelas ke temen. Hehehe." (wawancara dengan Calvin, 22 Februari 2021)

Prinsip dramaturgi selanjutnya yang ditemukan dalam penelitian ini adalah peran. Peran merupakan ekspektasi yang didefinisikan secara sosial dan dimainkan oleh seseorang dalam kehidupan sehari-hari (Suneki \& Haryono 2017). Menurut Goffman peran diibaratkan sebagai topeng, dimana aktor bebas memilih topeng mana yang akan ia kenakan saat berperan dalam dunia sosial. Dalam hal ini, peneliti membagi peran yang dilakukan oleh para informan menjadi dua. Peran pertama adalah saat informan berada di panggung depan (front-stage) atau di hadapan keluarga dan masyarakat, yaitu menjadi perempuan yang menganut prinsip heteronormativitas, memiliki fantasi romansa pasangan heteroseksual, feminim, dan mengikuti aturan norma dan agama yang berlaku. Dalam artikel yang ditulis oleh Putri Andam Dewi yang berjudul Komunitas Fujoshi di Kalangan Perempuan Indonesia (2012), dijelaskan bahwa konstruksi sosial dan budaya heteronormatif di Indonesia membentuk identitas bagi perempuan Indonesia yang harus feminim dan menyukai romansa percintaan antara laki-laki dan perempuan. Namun, yang terjadi pada fujoshi, dalam hal ini termasuk para fujoshi dari Indonesia yang menyukai kisah romantis sesama laki-laki, merupakan ketidaknormalan dalam prinsip heteronormatif yang dianut oleh masyarakat Indonesia. Dengan meminjam kritik Judith Butler tentang heterosexual matrix, dimana ketika seseorang lahir dengan jenis kelamin tertentu secara biologis kemudian akan dibangun identitas yang sifatnya mengikat di atasnya, jika perempuan harus feminin, jika laki-laki harus maskulin dan harus menyukai lawan jenis, Dewi menyatakan bahwa fenomena fujoshi dianggap tidak normal karena ia tidak dapat dijelaskan dengan teori heterosexual matrix tersebut (Dewi, 2012).

Peran kedua adalah peran yang dilakukan oleh para informan yang memiliki pandangan tidak mendukung homoseksualitas pada grup-grup fujoshi salah satunya grup WA FR, yaitu dengan menjadi fujoshi yang menyetujui homoseksualitas:

"Kalo aku sih udah lama jadi K-Popers. 1112 lah (menjadi K-Popers dan fujoshi mirip). Ya biasa aja aku tuh, nggak disebut nyamar juga sih, kan balik lagi nonton BL buat hobi aja. Kalo masalah ngedukung NO." (wawancara dengan Daisy, 14 Maret 2021) 
Peran pertama seringkali dilakukan dengan tujuan untuk menutupi identitas informan sebagai perempuan penggemar konten homoseksual. Sedangkan peran kedua bertujuan untuk menutupi pandangan informan yang tidak mendukung homoseksual, dan agar informan dapat tetap diterima di grup-grup fujoshi seperti grup WA FR. Kedua peran tersebut dimainkan oleh para informan dalam penelitian ini untuk mempertahankan citra dan kesan dirinya dan juga kelompok-kelompoknya. Galbraith dalam artikelnya menyatakan bahwa di negara-negara yang menganut prinsip heteronormatif, fujoshi menjalani hidup yang heteronormatif juga, meskipun memiliki fantasi yang cenderung aneh. Dengan menjadi fujoshi mereka menganggap bahwa fantasi mereka tidak lebih dari sekedar cara bermain-main, hal ini mengacu pada tradisi lama Jepang yang disebut asobi, yang berarti permainan yang berada di luar ekspektasi dan aturan sehari-hari (Galbraith, 2011). Sama halnya dengan fujoshi di Indonesia, mereka menganggap karya-karya fiksi BL hanyalah sebagai hiburan semata yang didasari oleh faktor cerita yang lebih menarik dari konten dengan romansa heteroseksual, bosan dengan romansa konten heteroseksual, dan tertarik dengan visualisasi tokoh atau karakter yang nyaris sempurna sebagai laki-laki idaman (ideal) bagi para fujoshi.

Prinsip dramaturgi selanjutnya adalah komunikasi keluar dari karakter, yaitu sikap yang dilakukan oleh para aktor saat mereka tidak sengaja mengungkapkan fakta yang akan merusak peran awal mereka (Manning, 1992). Dalam konteks penelitian ini, misalnya, agar informan tidak ketahuan bahwa dirinya adalah seorang fujoshi, mereka akan melakukan beberapa kamuflase. Misalnya, sebelum menjadi fujoshi informan Michan, Julay, dan Daisy awalnya merupakan seorang K-Popers. Ketika mereka mengunggah story di akun media sosial dan temannya mencurigai, mereka akan beralasan bahwa orang atau aktor yang mereka unggah tersebut merupakan artis-artis Korea (орра-орра). Selain itu informan seperti Caroline yang merupakan penggemar anime dan manga juga melakukan hal yang sama:

"Jadi aku udah biasa menghadapi macam-macam orang, ya otomatis bisa tau harus bersikap bagaimana. Mereka taunya aku cukup eksentrik dan suka Jejepangan, biasanya yang orang tau cuma gitu." (wawancara dengan Caroline, 24 Februari 2021)

Bagi informan yang menyembunyikan dirinya sebagai fujoshi mereka akan sangat berhati-hati agar tidak ketahuan identitas dirinya. Contohnya informan Michan yang menggunakan gambar anime BL sebagai wallpaper dan latar belakang papan ketik telepon genggamnya, namun, ia hanya menggunakan separuh gambar (gambar di-crop) yang menunjukkan satu tokoh saja (seharusnya satu pasangan homoseksual). Jadi ketika temannya bertanya tentang wallpaper telepon genggamnya, Michan akan menjawab bahwa karakter tersebut adalah karakter anime. Prinsip dramaturgi yang terakhir adalah manajemen kesan (impression management), yakni tindakan yang dilakukan oleh aktor untuk mempertahankan kesan yang dimilliki penonton kepadanya dan agar rahasia dirinya tidak terungkap (Arisandi, 2015). Bagi tipologi informan yang menyembunyikan identitasnya sebagai fujoshi, cara mempertahankan kesan bahwa ia adalah perempuan normal seperti pada umumnya adalah dengan cara kamuflase. Ketika teman-teman atau orang terdekat informan membahas isu homoseksual, informan tersebut akan pura-pura terkejut, seolah-olah ia tidak mengetahui adanya hal tersebut. Informan ini juga menyetujui asumsi-asumsi orang terdekatnya untuk menolak homoseksual:

"Tapi aku mau jujur aku fujo tapi kalau liat yaoi secara nyata nggak suka geli aja gitu. Nah cara nyembunyiinya jadi bunglon gitu. Kalau orang-orang ngehujat aku cuman bilang: iihh kok bisa yah, kaya nggak ada cewek aja. Gitu doang sih." (wawancara dengan Michan, 21 Februari 2021)

Kedelapan informan dalam penelitian ini, yang seluruhnya merupakan perempuan heteroseksual, faktanya mereka menyukai dan memiliki pasangan laki-laki. Hal ini secara otomatis membantu memperkuat kesan identitas diri mereka sebagai perempuan yang mengikuti konsensus norma masyarakat Indonesia tentang heteronormativitas. Saat di 
panggung depan, informan mematuhi aturan yang ada dalam masyarakat. Informan juga beribadah sesuai agama yang dianut masing-masing. Jadi, baik keluarga ataupun masyarakat tidak mengetahui jika informan tersebut memiliki kegemaran yang sebenarnya tabu dalam masyarakat atau dilarang dalam agama. Selain itu dalam grup-grup fujoshi, beberapa informan yang tidak mendukung homoseksualitas juga memberi kesan seolah-olah mereka menyetujui homoseksualitas dengan terus mengkonsumsi dan mengikuti update terbaru konten-konten BL, serta berpendapat bahwa orientasi seksual adalah hak masing-masing individu.

Penelitian ini menunjukkan bahwa para informan harus melakukan keenam prinsip dramaturgi yang telah dijelaskan di atas untuk menutupi identitas dirinya sebagai seorang fujoshi. Informan melakukan praktik dramaturgi, mereka menutupi identitas fujoshi-nya dengan cara berperan sebagai perempuan yang menganut prinsip heteronormativitas. Informan juga memberikan kesan yang berbeda pada setiap kelompok yang berbeda pula untuk mempertahankan dan memperkuat identitasnya, baik sebagai perempuan heteroseksual sesuai standar masyarakat dan perempuan penggemar karya-karya fiksi homoseksual.

Selain pilihan sikap pribadi masing-masing informan, harus diakui bahwa relasi kuasa patriarkis yang berlaku di Indonesia membawa pengaruh terhadap sikap informan dalam hal berterus-terang atau merahasiakan identitas fujoshi-nya. Relasi kuasa patriarki yang cenderung dominan di Indonesia membuat beberapa informan harus merahasiakan identitasnya sebagai fujoshi karena anggapan bahwa hal yang digemari fujoshi syarat akan muatan seksual apalagi bukan romansa heteroseksual. Informan takut akan dicap sebagai perempuan aneh yang tidak mengikuti norma bagaimana seharusnya seorang perempuan dalam budaya patriarki. Di negara Jepang, karya fiksi BL dianggap membawa sisi baru bagi para perempuan. Karena kuatnya dominasi patriarki di Jepang, konten fiksi BL dianggap membebaskan perempuan dari objek seksis para laki-laki. Konten fiksi BL menjadi konten pengganti yang berbeda dengan kenyataan dimana laki-laki selalu tampil mendominasi dan perempuan selalu menjadi pihak pasif yang mengikuti. Singkatnya fujoshi secara radikal telah mengubah prinsip homososialitas di mana perempuan dan kelompok minoritas seksual seringkali dimarjinalkan, menjadi prinsip di mana perempuan bebas dari dominasi laki-laki dan memungkinkan keduanya untuk mengambil bagian dalam relasi sosial gender dan seksual minoritas (Tanaka \& Ishida 2015). Walaupun tidak sampai dalam konteks melawan atau memberontak terhadap dominasi ideologi patriarki yang berlaku di Indonesia, namun relasi kuasa yang patriarkis tetap membawa pengaruh besar terhadap pilihan strategi negosiasi identitas diri informan sebagai seorang fujoshi.

\section{Simpulan dan Saran}

Dari penelitian yang telah dilakukan oleh peneliti dengan menggunakan pendekatan netnografi pada grup WA FR ini, dapat ditarik beberapa kesimpulan. Terdapat tiga tipologi identitas fujoshi dalam penelitian ini, yakni yang pertama adalah fujoshi yang tertutup (menyembunyikan identitasnya sebagai seorang fujoshi), kedua adalah fujoshi yang kondisional (menyesuaikan identitas dirinya sebagai fujoshi) dan yang ketiga adalah fujoshi yang terbuka (tidak menyembunyikan identitasnya sebagai seorang fujoshi). Sejumlah informan dalam penelitian ini melakukan praktik dramaturgi dengan cara kamuflase. Informan membedakan pada siapa, dimana, bagaimana, dan apa yang harus mereka perankan dan lakukan dipanggung depan (front-stage). Para informan juga memiliki dua kelompok sosial yang mereka ikuti, yakni keluarga dan masyarakat yang harus mereka hadapi di panggung depan (front-stage), serta yang kedua adalah grup-grup fujoshi di media sosial (salah satunya grup WA FR) sebagai panggung belakang (back-stage) para informan sebagai fujoshi. Dengan dua kelompok dan panggung yang berbeda, informan selanjutnya melakukan sejumlah strategi dramaturgi identitas melalui kinerja, peran, komunikasi keluar dari karakter, dan manajemen kesan yang berbeda pada setiap kelompok dan wilayahnya. Para fujoshi melakukan praktik dramaturgi dan negosiasi identitas ini dengan tujuan agar tetap dapat hidup harmonis dalam lingkungan masyarakat Indonesia yang cenderung heteronormatif. Penelitian tentang praktik dramaturgi identitas fujoshi ini diharapkan dapat menambah wawasan tentang berbagai aspek dunia para fujoshi 
serta dapat menjadi rujukan penelitian berikutnya tentang fujoshi terutama yang terkait dengan tema-tema gender, identitas, seksualitas, budaya patriarki, dan heteronormativitas.

\section{Daftar Rujukan}

Abraham, Y. (2010). Boys Love Thrives in Conservative Indonesia. In A. Levi, M. McHarry, \& D. Pagliassotti (Eds.), Boys Love Manga: Essays on the Sexual Ambiguity and Cross-Cultural Fandom of the Genre. McFarland \& Company, inc.

Arisandi, H. (2015). Buku Pintar Pemikiran Tokoh-Tokoh Sosiologi dari Klasik Sampai Modern. IRCiSoD.

Dewi, P. A. (2012). Komunitas Fujoshi di Kalangan Perempuan Indonesia. Lingua Cultura, 6(2), 173-182. https://doi.org/https://dx.doi.org/10.21512/lc.v6i2.404

Galbraith, P. W. (2011). Fujoshi : Fantasy Play and Transgressive Intimacy among "Rotten Girls" in Contemporary Japan. Chicago Journals, 37(1), 211-232. http://www.jstor.org/stable/10.1086/660182?origin=JSTOR-pdf

Goffman, E. (1959). The Presentation of Self in Everyday Life. Penguin.

Goffman, E. (1963). Stigma: Notes on the Management of Spoiled Identity. Penguin.

Husaini, A. (2015). LGBT di Indonesia Perkembangan dan Solusinya. INSISTS.

Kozinets, R. V. (2010). Netnography: Doing Ethnographic Research Online. In Sage Publications Ltd. Sage Publications Ltd. https://doi.org/10.2501/S026504871020118X

Kozinets, R. V. (2015). Netnography: Redefined. Sage Publications Ltd.

Manning, P. (1992). Erving Goffman and Modern Sociology. Polity Press.

McLelland, M. J. (2000). The Love Between "Beautiful Boys" in Japanese Women's Comics. $\begin{array}{llll}\text { Journal of } & \text { Gender } & \text { Studies, } & 1(9),\end{array}$ https://doi.org/https://doi.org/10.1080/095892300102425

McLelland, M., Nagaike, K., Suganuma, K., \& Welker, J. (2015). Boys Love Manga and Beyond. University Press of Mississipi.

Siyoto, S., \& Sodik, A. (2015). Dasar Metodologi Penelitian. Literasi Media Publishing.

$\mathrm{Su}$, W. (2019). The Power of Bromance in BL Fiction: A Homosexual Narrative in Chai Jidan's Addicted. Advances in Social Sciences Research Journal, 6(7), 505-517. https://doi.org/https://doi.org/10.14738/assrj.67.6829

Sugiura, Y. (2006). Fujoshika Suru Sekai: Higashi Ikebukuro no Otaku Joshitachi. Chuokoron Shinsha.

Suneki, \& Haryono. (2017). Paradigma Teori Dramaturgi terhadap Kehidupan Sosial. Civis, 2(2), $1-11$.

Tadzakaroh, D. N. (2017). Perempuan, Identitas, dan Komik Homoerotis. Universitas Islam Negeri Sunan Kalijaga.

Tanaka, H., \& Ishida, S. (2015). Enjoying Manga as Fujoshi: Exploring its Innovation and Potential for Social Change from a Gender Perspective. International Journal of Behavioral Science, 13(1), 77-85. https://doi.org/https://doi.org/10.14456/ijbs.2015.5

Turner, S. (2016). Yaoi Online: The Queer and Affective Practices of a Yaoi Manga Fan Community [Birckbeck, University of London]. https://core.ac.uk/download/pdf/33269163.pdf

Winduwati, S. (2015). Fujoshi Remaja dan Kenikmatan Bermedia YAOI (Studi Kasus pada Remaja Putri Penggemar Fiksi Romantis Homoerotis Jepang). Karya Ilmiah Dosen Fikom, Dinamika M, 1-22. http://journal.tarumanagara.ac.id/index.php/kidFik/article/view/2089 